\title{
SUEÑOS EN BLANCO Y NEGRO: LA EXPANSIÓN DE LA UFA EN BRASIL Y AMÉRICA LATINA
}

\author{
Dreams in Black and White: \\ Ufa's Expansion in Brazil and Latin America
}

WOLFGANG FUHRMANN ${ }^{\mathrm{a}}$

Universidad de Zúrich

DOI: $10.15366 /$ secuencias2020.52.003

\begin{abstract}
RESUMEN
La Ufa, la Universum Film AG de Berlín, Alemania, fue el único estudio cinematográfico que logró competir con los grandes estudios de Hollywood en los años 1920 y 1930. Con ciento cuarenta sucursales, agencias y salas de cine en todo el mundo, la Ufa fue un global player en el cine mundial. A pesar de su reputación, sabemos muy poco sobre la estructura de la Ufa en el exterior, por ejemplo, en América Latina. Basado en correspondencias de la Ufa con sus socios y otras fuentes primarias, el artículo presenta por primera vez una mirada a las diversas actividades de la Ufa en el continente, su estrategia de distribución, marketing y los problemas que la Ufa encontró en los países latinoamericanos. El siguiente artículo se enfocará en el mercado brasileño, donde la Ufa abrió el primer UFA-Palácio en 1936, en São Paulo. Para la Ufa, el palacio debería ser el inicio de su expansión en el mercado brasileño y en Suramérica; pero el sueño de una Ufa do Brasil terminó temprano con el inicio de la Segunda Guerra Mundial.
\end{abstract}

Palabras clave: Brasil, distribución, ideología nazi, América Latina, cine alemán, Ufa, Ufa Palacio

\begin{abstract}
The Ufa, Berlin's Universum Film AG in Germany, was the only film studio that managed to compete with the big Hollywood studios in the 1920s and 1930s. With 140 branches, agencies, and film theatres worldwide, Ufa was a global player in world cinema. Despite its reputation, little has been written about Ufa's structure abroad, in places like Latin America for instance. Based on Ufa's correspondences with its partners and other primary sources, the article presents for the first time a look at Ufa's various activities in the continent, its distribution strategy, marketing, and the problems Ufa encountered in different Latin American countries. The article will focus particularly on the Brazilian market, where Ufa opened the first UFA-Palácio (Ufa Palace) in 1936, in São Paulo. For Ufa, the palace was to be the beginning of its expansion into the Brazilian market and into South America; but the dream of an Ufa do Brasil ended early with the outbreak of World War II
\end{abstract}

Keywords: Brazil, distribution, German cinema, Latin America, Nazi Ideology, Ufa, Ufa Palace

[a] Wolfgang Fuhrmann es historiador de cine e investigador asociado al Departamento de Cine de la Universidad de Zúrich. Es Doctor en Estudios Cinematográficos de la Universidad de Utrecht, Holanda, autor de la publicación Imperial Projections. Screening the German Colonies (Berghahn, 2015) y de múltiples publicaciones y ponencias sobre el cine temprano, cine etnográfico, cine documental, cine transnacional y las relaciones cinematográficas entre América Latina y los países germanoparlantes. Docente en Alemania, Suiza, Canadá, Brasil y Colombia, su más reciente proyecto de investigación indaga las relaciones cinematográficas de por lo menos un siglo entre Brasil y Alemania. E-mail: wolfgang.fuhrmann@gmail.com 


\section{Introducción}

Durante la década de los años treinta, el empresario brasileño de cine Ugo Sorrentino resumió la buena reputación en Brasil de la Ufa (Universum Film AG de Berlín, Alemania) de una manera encantadora, que probablemente muchos otros públicos nacionales en América Latina hubieran compartido: no importa cuál película de Alemania fuera mostrada en Brasil. Para el público brasileño, cada película alemana era una película Ufa: Um-filme-alemão ${ }^{1}$.

La Ufa fue el único estudio cinematográfico que logró competir con los grandes estudios de Hollywood en los años veinte y treinta. Fundada el 18 de diciembre de 1917, la Ufa se desarrolló en la República de Weimar como el segundo mayor imperio del cine en el mundo, con sus propios estudios en Babelsberg, cerca de Berlín, su propio sistema de distribución y salas de cine. La Ufa tuvo ciento cuarenta sucursales, agencias y salas de cine en todo el mundo. De esta manera, fue un global player en el cine mundial. Pese a su reconocimiento, la estructura de la Ufa en el exterior, por ejemplo, en América Latina es poco conocida.

El presente artículo es una aproximación a la presencia de la Ufa en América Latina, a partir de documentos de la Ufa encontrados y consultados en el Archivo Nacional de Berlín y complementados con fuentes latinoamericanas. Para el caso de la Ufa en Brasil, la Hemeroteca Digital Brasileira, que constituye una plataforma digital y repositorio de periódicos y revistas digitalizados de manera OCR, permitió seguir la historia de la Ufa en Brasil en términos de publicidad en los periódicos del país ${ }^{2}$.

Si bien los documentos en Berlín sobre la actividad de la Ufa fuera de Alemania presentan algunos vacíos, permiten entender cómo la Ufa realizó la distribución y la venta de sus filmes en países de América Latina y en Brasil, por ejemplo, cuáles fueron los planes para entrar a ese mercado y establecer allí sucursales.

Además de libros de fotografías sobre la historia de la compañía, en el fundamento de la investigación sobre la Ufa están la antología de Hans-Michael Bock y Michael Töteberg, Das Ufa-Buch. Kunst und Krisen, Stars und Regisseure, Wirtschaft und Politik; y la monografía de Klaus Kreimeier de 2002, Die Ufa-Story: Geschichte eines Filmkonzerns ${ }^{3}$. Publicada con motivo del centenario de la Ufa en 2017, la antología Linientreu und populär: Das Ufa-Imperium 1933-1945, de Rainer Rother y Vera Thomas ${ }^{4}$, se enfoca en varios aspectos de la empresa durante el nacionalsocialismo. Un importante análisis sobre la producción de versiones multilingües de la Ufa y su distribución en el exterior lo hace Chris Wahl en Sprachversionsfilme aus Babelsberg: die internationale Strategie der Ufa 1929-1939, de 20095. Hasta hoy, la investigación sobre la Ufa en el exterior es más limitada y se centra, en su mayoría, en la época del nacionalsocialismo: la antología de Roel Vande Winkel y David Welch Cinema and the Swastika, The International Expansion of Third Reich ofrece un buen resumen sobre el papel del cine nazi en el mundo ${ }^{6}$. Ingo Schiweck investiga el cine alemán en los Países Bajos ${ }^{7}$, Paul Lesch se dedica a la recepción de las películas alemanas en Luxemburgo ${ }^{8}$. Karl Sierek investiga la relación entre la Ufa en Berlín y Japón/China, particularmente sobre el distribuidor japonés Kawakita Nagamasa ${ }^{9}$. María Antonia Paz y Julio Montero siguen la influencia del cine nazi en España en su investigación La larga sombra de Hitler ${ }^{10}$. El historiador brasileño Flaviano Bugatti Isolan hace importantes contribuciones sobre la recepción del cine alemán y las películas de la Ufa en el sur de Brasi1 ${ }^{11}$. Finalmente, las informaciones sobre el cine alemán publicadas en los periódicos de Porto Alegre y Santa Cruz do
[1] Ugo Sorrentino, «200 brasilianische Kinos für den deutschen Film» (Film Kurier, 28 de julio de 1934), BArch, R 109-1/5379.

[2] <https://bndigital.bn. gov.br/hemeroteca-digital> $(05 / 05 / 2020)$. La crítica de que una búsqueda por palabras clave puede resultar superficial en una investigación puede ser respondida con el argumento de que la HBD también ofrece el estudio de artículos o ediciones enteros para contextualizar los resultados. Al final, el trabajo de historiador es para contextualizar los datos.

[3] Hans-Michael Bock y Michael Töteberg (eds.), Das UfaBuch: Kunst und Krisen, Stars und Regisseure, Wirtschaft und Politik: die internationale Geschichte von Deutschlands grösstem Film-Konzern (Frankfurt am Main, Zweitausendeins, 1992). Klaus Kreimeier, The Ufa Story: A History of Germany's Greatest Film Company, 1918-1945. Translated by Robert and Rita Kimber (Berkeley, Los Angeles, London: University of California Press, 1996) .

[4] Rainer Rother y Vera Thomas, Linientreu und populär: Das Ufa-Imperium 1933-1945 (Berlin, Bertz + Fischer, 2017).

[5] Chris Wahl, Sprachversionsfilme aus Babelsberg: die internationale Strategie der Ufa 19291939 (Munich, Edition Text und Kritik, 2009).

[6] Roel Vande Winkel and David Welch, Cinema and the Swastika: The International Expansion of Third Reich Cinema (Basingstoke, Palgrave Macmillan, 2007).

[7] Ingo Schiweck, «[...] weil wir lieber im Kino sitzen als in Sack und Asche»: der deutsche Spielfilm in den besetzten Niederlanden 1940-1945 (Münster: Waxmann, 2002).

[8] Paul Lesch, Heim ins UfaReich?: NS-Filmpolitik und die Rezeption deutscher Filme in Luxemburg 1933-1944 (Trier, Wissenschaftlicher Verlag Trier, 2002, traducción del francés por George Hausemer). 
[9] Karl Sierek, Der lange Arm der Ufa. Filmische Bilderwanderung zwischen Deutschland, Japan und China. 1923-1949 (Wiesbaden, Springer, 2018). Verlag Trier, 2002).

[10] María Antonia Paz y Julio Montero, La larga sombra de Hitler. El cine nazi en España (19331945) (Madrid, Cátedra, 2009).

[11] Flaviano Isolan Bugatti, Das páginas à tela: a imprensa rio-grandense e o cinema alemão na década de 1930 (Porto Alegre e Santa Cruz do Sul: um estudo comparativo) (Santa Cruz do Sul, Edusinc, 2006). Flaviano Isolan Bugatti, Filmabsatzgebiet Brasilien: Die Rezeption des deutschen Films in Brasilien in den 1920er und 30er Jahren (Tesis doctoral, Berlín, Universidad Técnica de Berlín, 2010).

[12] Un resumen sobre las actividades de los extranjeros en el área del cine y de televisión en Brasil se encuentra en Jurandyr Noronha, Dicionário Jurandyr Noronha de Cinema Brasileiro: Os que vieram de otras terras (Rio de Janeiro, EMC Edições, 2015).

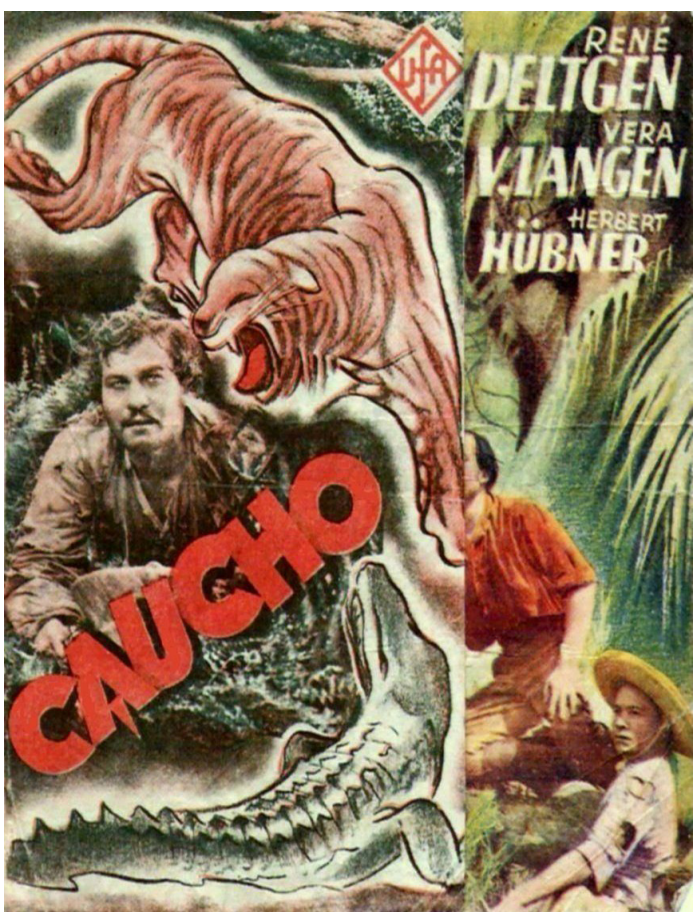

Cartel de Caucho (Kautschuk, Eduard von Borsody, 1938). la región.
Sul, al sur de Brasil, permiten trazar una idea sobre la popularidad del cine alemán en

\section{El mercado en América Latina}

Las relaciones comerciales de la Ufa con los países de América Latina incluían la promoción y la venta de películas. La Ufa nunca persiguió el objetivo de producir películas conjuntas, es decir, coproducciones en América Latina. Los países latinoamericanos sirvieron de escenario a películas culturales y expedicionarias como König Amazonas (William McGovern, 1925), Die grüne Hölle (August Brückner, 1930) o como telón de fondo de películas de aventuras como Caucho (Kautschuk, Eduard von Borsody, 1938). De las relaciones transnacionales de la Ufa en América Latina no solo resultaron películas como las arriba mencionadas; también cuentan, por ejemplo, las biografías de antiguos empleados de la Ufa como los hermanos Franz y Edgar Eichhorn, quienes encontraron su segundo hogar en el Brasil, o los negocios con socios de ascendencia alemana ${ }^{12}$.

Si bien la Ufa mantuvo relaciones comerciales con los mercados de América Central, Cuba y los estados más pequeños de América del Sur, se les trató como negocios al azar (Zufallsgeschäfte).

La situación económica en Alemania después de la inflación en 1923 obligó a la Ufa a abrir otros mercados. América Latina fue un mercado interesante e importante para la empresa, especialmente en Argentina, Brasil y Chile, dada la numerosa inmigración alemana en estos países.

Antes de la Primera Guerra Mundial, el mercado latinoamericano fue dominado por producciones de Francia e Italia. Hollywood empezó a dominar los mercados apenas durante el transcurso de la guerra. En 1916, solamente el 12\% de las películas distribuidas en América del Sur vinieron de los Estados Unidos ${ }^{13}$. Después de Australia, Brasil y Argentina se convirtieron en los mercados más importantes en la importación de películas de Hollywood, que para 1929 dominó los dos mercados con un $85 \%{ }^{14}$.

El cine alemán nunca estuvo en la posición de dominar un mercado nacional en América Latina. Sin embargo, logró un porcentaje estable en los años veinte y treinta. Después de la Primera Guerra Mundial, Alemania aumentó su aportación al mercado brasilero con un $8 \%$ en $1922^{15}$. La cuota bajó a $1,9 \%$ en 1925 y se estableció en 1929, al final de la década, en un $7,7 \%{ }^{16}$. En Colombia, en 1930, las películas alemanas ocuparon el segundo lugar en los cines, después de Hollywood y antes de Francia ${ }^{17}$. Una estabilización similar se puede observar en el mercado argentino. En 1935, el cine alemán fue más fuerte que el cine francés o el italiano en ese país ${ }^{18}$. Aunque la dominación del mercado por parte de Hollywood nunca estuvo en peligro, la alta calidad de las producciones alemanas fue reconocida ${ }^{19}$. 
La toma del poder por parte de Hitler no supuso una carga para las relaciones comerciales de la Ufa en los primeros años del Tercer Reich, y se garantizaron exhibiciones de películas alemanas hasta los años cuarenta. Los países de América Latina no participaron en la Segunda Guerra Mundial sino hasta después de 1941. Muchos gobiernos latinoamericanos mantuvieron buenas relaciones con Alemania y simpatizaron con el régimen de Hitler. Sin embargo, la situación fue cambiando con el paso de los años, y cada vez se hizo más difícil el desenvolvimiento del mercado cinematográfico, hasta verse incluso paralizado.

Distribuir películas alemanas en países de habla española y portuguesa fue un reto para la Ufa. En los países de habla española, era mucho más fácil comercializar producciones de México o España que las películas en lengua extranjera, las cuales tenían que ser subtituladas, dobladas o producidas a un costo elevado en una versión multilingüe. La fundación en 1936 de la productora germano-española Hispano Filmproduktion fue una de las decisiones estratégicas para no solamente entrar al mercado español y estabilizar el axis entre Franco y el Tercer Reich, sino también usar a la productora como un trampolín para facilitar la distribución de producciones alemanas en América Latina.

Más importante que la función de la Hispano Filmproduktion fue, sin embargo, el contacto con compradores y distribuidores en los países de América Latina. $^{20}$

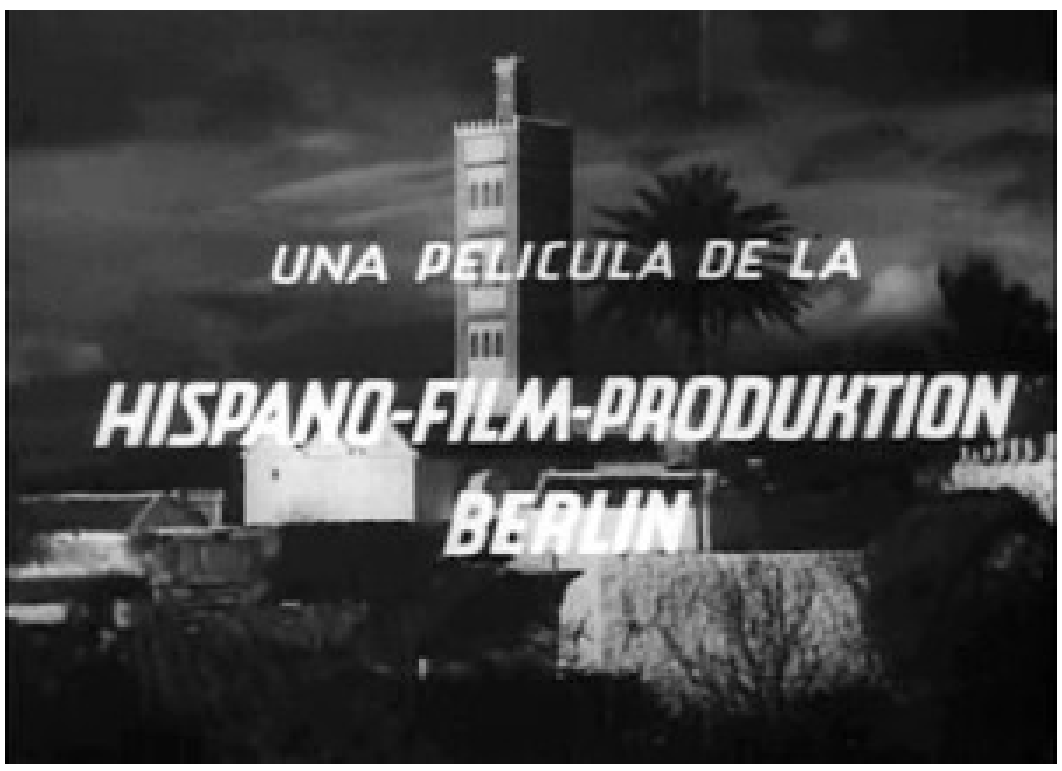

Hispano Filmproduktion, Fotograma de La canción de Aixa /Hinter Haremsgittern (Florian Rey, 1939)

\section{La red de habla alemana de la Ufa}

La Ufa tenía socios en los países de América Latina: Cinematográfica Calderón en México, Cine Colombia en Colombia y Di Fiore en Argentina. Pero eran sobre todo una red de migrantes germanoparlantes, y el interés económico de las empresas alemanas desde México hasta Argentina, los que aseguraban las ventas en el extranjero.
[13] Kristin Thompson, Exporting Entertainment: America in the World Film Market 1907-1934 (Londres, British Film Institute, 1985), p. 78.

[14] Department of Commerce, Bureau of Foreign and Domestic Commerce (ed.), Motion Pictures in Argentina and Brazil, Trade Information Bulletin, no. 630, 1929, p. (II).

[15] Randal Johnson, Film Industry in Brazil: Culture and the State (Pittsburgh, University of Pittsburgh Press, 1987), p. 36.

[16] Kristin Thompson, Exporting Entertainment, p. 139.

[17] Leidy Paola Bolaños Florido, Cine silente: una historia de Hollywood en Colombia (19101930) (Medellín, La Carreta Editores, 2020), p. 98.

[18] Valeria Galván y Marina Moguillansky, «Escenas de la Alemania nazi en las pantallas porteñas (1933-1945)», (III Coloquio Internacional de Cine e Historia, UNILA, Foz de Iguazú, 2 y 3 de diciembre de 2018).

[19] Department of Commerce, Motion Pictures in Argentina and Brazil, p. 5 .

[20] Manuel Nicolás Meseguer, Hispano Film Produktion, Una aventura españolista en El cine del Tercer Reich (1936-1944) (Santander, Shangrila, 2017). 
[21] Gerald D. Feldman Hugo Stinnes, Biographie eines Industriellen, 1870-1924 (Munich, C.H.Beck, 1998), p.578).

[22]«Max Glücksmann». <http:/ www.victorian-cinema.net/ glucksmann> (05/05/2020).

[23] «Contracto (Vertrag), BArch R 109-I/2079.

[24] Correspondencia, Deutsche Gesandtschaft in Buenos Aires an Ufa, 22 de octubre de 1919, BArch, R 109-I/71957.

[25] Correspondencia, Ufa an Deutsche Gesandtschaft in Buenos Aires, 5 de noviembre de 1919, BArch, R 109-I/71957.
El primer representante de la Ufa en Sudamérica fue el argentino Emilio Kinkelin, quien mantuvo un estrecho contacto con la prominente familia empresarial alemana Stinnes. Kinkelin permaneció en Alemania durante la Primera Guerra Mundial como agregado militar. De civil, representó a Stinnes y a la Ufa en Buenos Aires después de la guerra, en la década de los años veinte ${ }^{21}$.

Uno de los socios más importantes de la industria cinematográfica alemana en Argentina fue el austrohúngaro Max Glücksmann, quien emigró siendo joven de Austria a Argentina con su familia en 1890, y a quien se considera hasta hoy un pionero del cine argentino ${ }^{22}$. Con más de cien teatros en Argentina, Chile y Perú, Glücksmann era un socio competente.

Activo en la industria fonográfica y cinematográfica, Glücksmann adquirió en 1919 — a través de la Internationale Filmvertriebs-Gesellschaft_, para Argentina, Bolivia, Chile, Perú, Uruguay y Paraguay, «los derechos de monopolio para todas las películas producidas por las empresas manufactureras del Grupo Ufa y para aquellas películas alemanas cuyos derechos de distribución para su área de monopolio siguen siendo propiedad de Ufa para países extranjeros hoy en día» ${ }^{23}$.

Las películas vendidas por la Ufa a Glücksmann debían convertirse en la competencia de las producciones norteamericanas. Para alcanzar este propósito, Glücksmann estaba obligado a dar la misma publicidad a las estrellas de cine alemanas de las películas adquiridas que a las americanas.

La elección de hacer de Glücksmann un socio de la Ufa no fue incontrovertible. Se dijo que incitó a la agitación contra Alemania durante la guerra ${ }^{24}$. Glücksmann argumentaba que, si no hubiese presentado en Buenos Aires las películas de los enemigos de Alemania durante la guerra, su supervivencia económica estaría amenazada ${ }^{25}$. Esta pudo haber sido una de las razones por las cuales la Ufa contactó a Adolfo Zicovich-Wilson, dueño de la Wilson\&Cia desde mediados de los años veinte. Zicovich-Wilson siguió siendo el socio de la Ufa hasta finales de los años treinta, mientras que Glücksmann continuó con la exhibición de producciones de la Ufa.

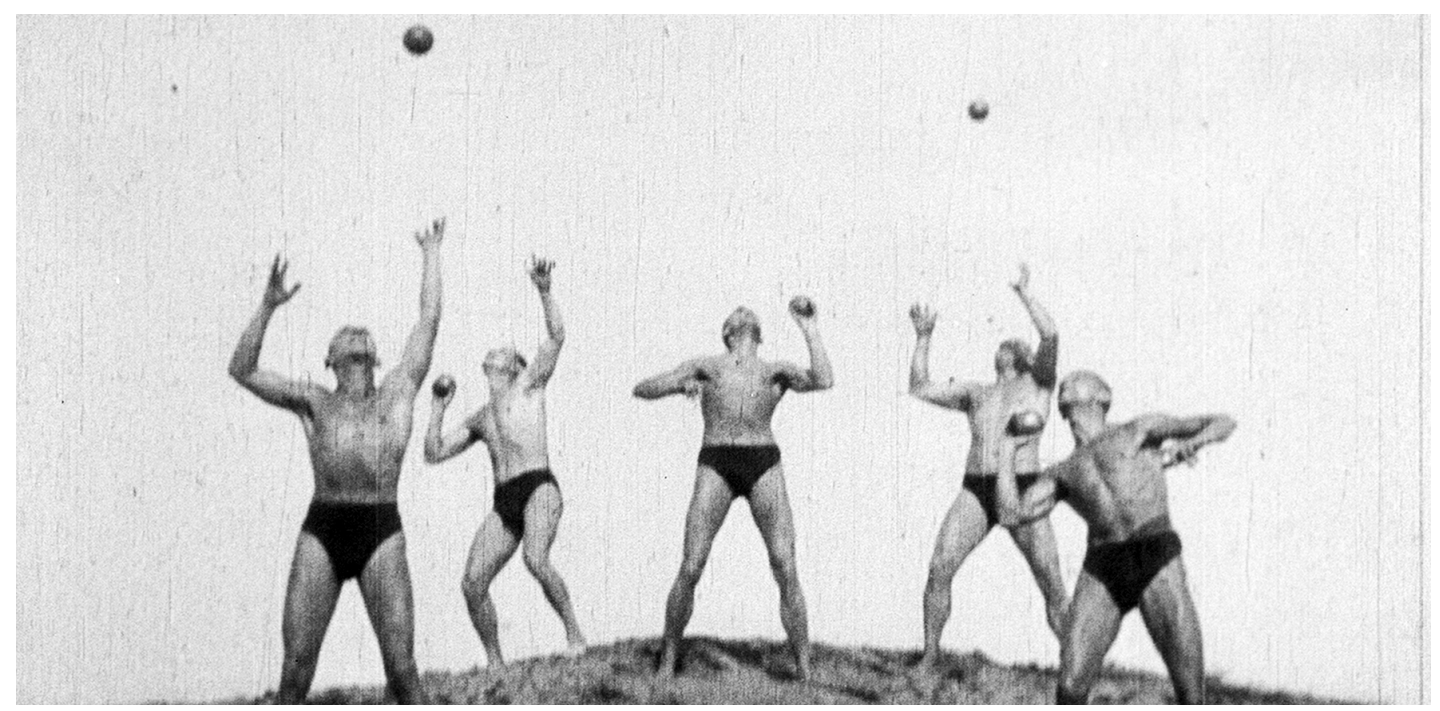

Fotograma de El camino hacia la belleza o El camino de la fuerza y de la belleza (Wege zur Kraft und Schönheit, Nicholas Kaufmann, Wilhelm Prager, 1925). 
En agosto de 1938, la compañía terminó la colaboración con Zicovich-Wilson por razones político-culturales, como lo expuso la Ufa en documentos empresariales ${ }^{26}$. Zicovich-Wilson era judío e intolerable para la Ufa como socio. Durante los años siguientes, la Ufa contrató a Hans (Juan) Biester. El grupo regional del Partido Nacionalsocialista Obrero Alemán en Argentina criticó la contratación de Biester por su colaboración anterior con Zinovich-Wilson. Como no había otro experto ciudadano del Reich alemán (Reichsdeutscher Fachmann) disponible, la Ufa se decidió por él ${ }^{27}$.

Pese a sus gestiones, no fueron Glücksmann o Wilson quienes establecieron a la Ufa como una productora de películas de alta calidad. Juan Probst, cuyo oficio muy probablemente era ser un profesor de origen alemán que dirigió la Cátedra de Literatura Alemana de la Universidad de Buenos Aires ${ }^{28}$, representaba a la productora alemana Terra Films en Buenos Aires en los años veinte. Fue incorporado en la empresa de Wilson en $1924^{29}$. Anuncios publicitarios de Probst en la revista argentina de cine Excelsior muestran que, entre 1925 y 1926, películas alemanas como El camino hacia la belleza, también conocida en español como El camino de la fuerza y de la belleza (Wege zur Kraft und Schönheit, Nicholas Kaufmann, Wilhelm Prager, 1925) ${ }^{30}$, El bailarín de mi mujer ${ }^{31}$ (Der Tänzer meiner Frau, Alexander Korda, 1925), o El sueño de un vals (Ein Walzertraum, Ludwig Berger, 1925) ${ }^{32}$ fueron promocionadas por primera vez junto con el reconocido símbolo de la Ufa.
[26] Vorlage für Vorstandssitzung (presentación para la reunión de la junta directiva), 14 de febrero de 1940, BArch, R 109-I/5465.

[27] Gedächtnisvermerk, Argentinien-Besprechung (nota conmemorativa, reunión-Argentina), 29 de septiembre 1938, BArch, R $109-\mathrm{I} / 5430$.

[28] Regula Rohland, reseña de «Franka Bindernagel: Deutschsprachige Migranten in Buenos Aires. Geteilte Empfindungen und umkämpfte Geschichtsbilder 1910-1932» (Iberoamericana, vol. 19, n. $\left.^{\circ} 71,2019\right)$, p.318.

[29] Fernando Martín Peña, «Metropolis Found».

$<$ https://web.archive.org/ web/20141016052747/http:// www.fipresci.org/undercurrent/ issue_0609/pena_metropolis. $\mathrm{htm}>(02 / 05 / 20)$.
Hollmann y Cía., una filial de la fábrica de rodamientos Friedrich Hollmann A.G. de Wetzlar, en Alemania, y la empresa de distribución de películas Eugenio Motz y Cía. — que según el membrete se había especializado en películas europeas - fueron las distribuidoras de las películas de la Ufa en México durante la década de los años veinte. La Ufa había concedido a Hollmann el uso de su marca en el verano de $1920^{33}$, pero pidió retomarla en 1921. La razón fue que la Ufa registró su marca a nivel internacional. Documentos que datan de los años cuarenta indican que la Ufa planeó establecer relaciones comerciales con Cinematográfica Calderón, una de las empresas más conocidas en la historia del cine mexicano ${ }^{34}$.

En Guatemala, la compañía Suhr, Sapper \& $\mathrm{Co}^{35}$, que fuera principalmente activa en el negocio del café, y la empresa Diestel, Hastedt $\& \mathrm{Co}^{36}$, único distribuidor de la marca B.M.W. en el país, compraron las películas de la Ufa.

En Colombia, la empresa comercial de Hamburgo H.A. Sierau \& Co. anunció en 1938 su interés en vender películas de la Ufa en el país a la empresa alemana A. Stapff \& Co. ${ }^{37}$. En Chile, la Ufa logró que el fotógrafo austríaco Roberto Schmutzer y la empresa Schmutzer \& Cia fueran socios distribuidores durante la década de los años treinta ${ }^{38}$.

La discusión sobre la actitud antialemana de Max Glücksmann, la separación de Adolfo Zinovich-Wilson en Argentina por su fe judía y la dificultad de encontrar

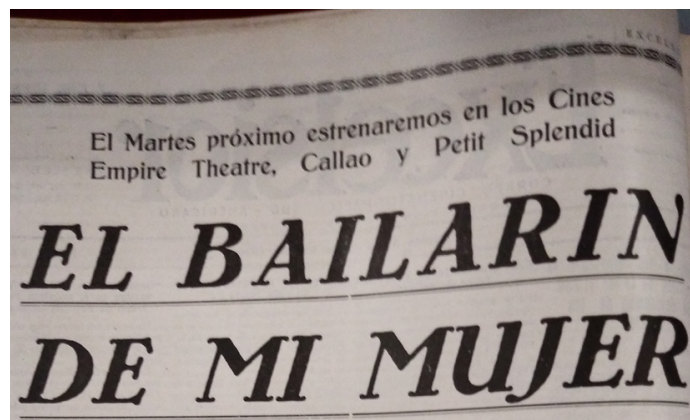

La más fina y audaz de las comedias reideras sacadas del conocido vodevil de Arnoud y Bousquet, será otro triunfo de la

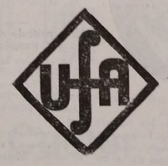

Continúa el gran suceso de

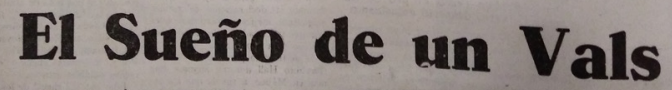

del famoso maestro STRAUSS

Cinematográfica $\mathbf{T} \mathbb{E}$ R

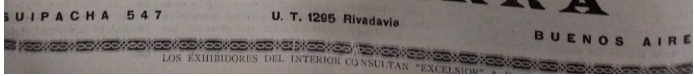

Anuncio publicitario, El bailarín de mi mujer (Der Tänzer meiner Frau, Alexander Korda 1923) (Excelsior, no. 643, 9 de julio 1926). 


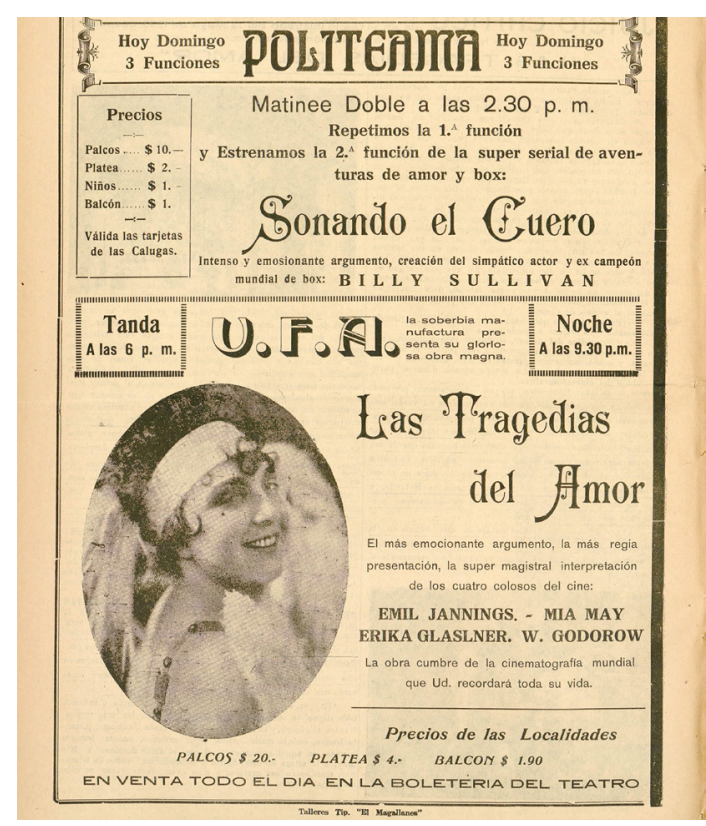

Anuncio publicitario, Las tragedias del amor (Tragödie der Liebe, Joe May, 1923) (Cine Social, no.24), p.4 (Chile).

Alemanes del Reich (Reichsdeutsche) en el exterior que cumplieran los requerimientos de la Ufa, tras la presión de los Estados Unidos en América Latina para posicionarse contra la Alemania Nazi, causaron problemas a la Ufa para desarrollar relaciones comerciales estables en toda América Latina. La orientación ideológica de la Ufa en los años treinta como empresa aria impidió repetidamente ganar nuevos clientes, fuera porque los socios comerciales eran de ascendencia judía o porque se consideraran políticamente poco fiables. Una red de habla alemana era importante, mas no necesariamente garante para el éxito en el exterior. Igualmente relevante era cumplir las expectativas visuales y narrativas en los países para el éxito del negocio cinematográfico transatlántico.

\section{Públicos y mentalidades}

En las revistas alemanas de cine es posible encontrar, una y otra vez, artículos sobre las preferencias de los públicos en el exterior. En 1920, la revista Der Film reportó que el público uruguayo prefería películas de drama y

[30] Anuncio publicitario (Excelsior, . $^{\circ}$ 598, 26 de agosto de 1925).

[31] $N$ del E. Estrenada en España como La fiebre de la danza.

[32] Anuncio publicitario (Excelsior, n. ${ }^{\circ} 640,18$ de junio de 1926).

[33] Aurelio de los Reyes, «El cine alemán y el cine soviético en México en los años veinte» (Journal of Film Preservation, n. $\left.{ }^{\circ} 60 / 61,2000\right)$, p. 51.

[34] Vorstandssitzung, 24 de junio de 1941, BArch, R 109-I/1613.

[35] Vorstandssitzung, 23 de noviembre de 1934, BArch, R $109-\mathrm{I} / 1029 \mathrm{c}$.

[36] Abschrift (transcripción), Diestel Hastedt \& Co, 7 de mayo de 1941, BArch, R 109-I/1611.

[37] Correspondencia, Ufa an Reichsfilmkammer Fachgruppe Filmaussenhandel, 29 de octubre de 1938, BArch, R 109-I/1611.

[38] Se desconoce la entrada exacta de Schmutzer en el comercio de Ufa. En octubre de 1939, Schmutzer le hace saber a Ufa que el comercio de películas alemanas ya no era lucrativo para él. Vermerk, Punkt 6: Peru, Chile, Bolivien, 4.10.1939, BArch, R 109-I/1611. policíacas; mientras que, al público colombiano, con preferencia por las producciones francesas e italianas, le encantaban las películas del «gran mundo», es decir, «lindos baños y elegantes espacios interiores $»^{39}$. En los respectivos países fueron realizadas evaluaciones sobre las preferencias del público, a fin de satisfacer sus gustos y ofrecerles producciones apropiadas. Las evaluaciones también se encuentran entre los documentos archivados de la Ufa: en Venezuela, el público prefería películas con mucho movimiento y buena música, como Barcarole ${ }^{40}$ (Gerhard Lamprecht, 1935), El congreso se divierte (Der Kongress tanzt, Eric Charell, 1931) o El barón gitano (Zigeunerbaron/ Le baron tzigane, Carl Hartl, 1935). En Chile, en cambio, eran predilectas las «grandes piezas de escenografía con un tema ligero y buena música ligera», en lugar del «arte serio» como Traumulus ${ }^{41}$ (Carl Froelich, 1935). En Colombia, el público amaba «las películas de opereta, las comedias, las películas con mucha trama y tan poco diálogo como sea posible». Los argentinos, por otro lado, daban prelación a las películas de la vida real: como republicano no tendría mucho sentido ver sobre «príncipes y princesas y cosas asíi ${ }^{42}$. Las ventas no siempre cumplieron los deseos del público: se presentaron algunas quejas sobre películas alemanas en su versión francesa y fueron solicitadas versiones alemanas con subtítulos en español ${ }^{43}$.

La Ufa se vio confrontada a inconvenientes relacionados con el personal, la red de habla alemana o la mentalidad de los diferentes públicos nacionales. Para evitar o superar a futuro estos problemas, el caso de la Ufa en Brasil mostró cómo la compañía fortaleció su sistema de sucursales en vez del sistema de ventas y representantes ${ }^{44}$.

\section{El ejemplo de Brasil}

Un mercado muy importante para la Ufa fue Brasil, país en el cual la empresa encontró condiciones económicas y políticas favorables. Brasil y Alemania sostuvie- 
ron tradicionalmente una sólida relación económica. Entre 1818 y hasta finales de los años veinte del siglo $\mathrm{xx}$, casi doscientos mil alemanes inmigrantes llegaron a Brasi ${ }^{45}$. El aumento de brasileños de origen alemán en el país, los llamados Teuto-Brasileiros, se dio paralelamente a un crecimiento inversionista en Brasi ${ }^{46}$. De forma continua, Alemania fue uno de los más importantes socios comerciales de la economía brasileña, relación que se vio interrumpida solo por la Primera Guerra Mundial. Hasta la Segunda Guerra Mundial, Alemania superó a los Estados Unidos como principal proveedor de productos para el mercado brasileño. La fuerte relación entre ambos países también se dio a nivel político. La lucha contra el comunismo generó una cercanía político-ideológica entre Brasil y Alemania, incluso con vínculos entre la Gestapo y la policía brasileña ${ }^{47}$. El robusto aparato de propaganda nacionalsocialista, que incluyó el control de la producción cinematográfica, gozó de gran admiración por parte de las autoridades brasileñas ${ }^{48}$. La buena amistad entre los gobiernos - Getulio Vargas llamó en 1936 a Hitler su

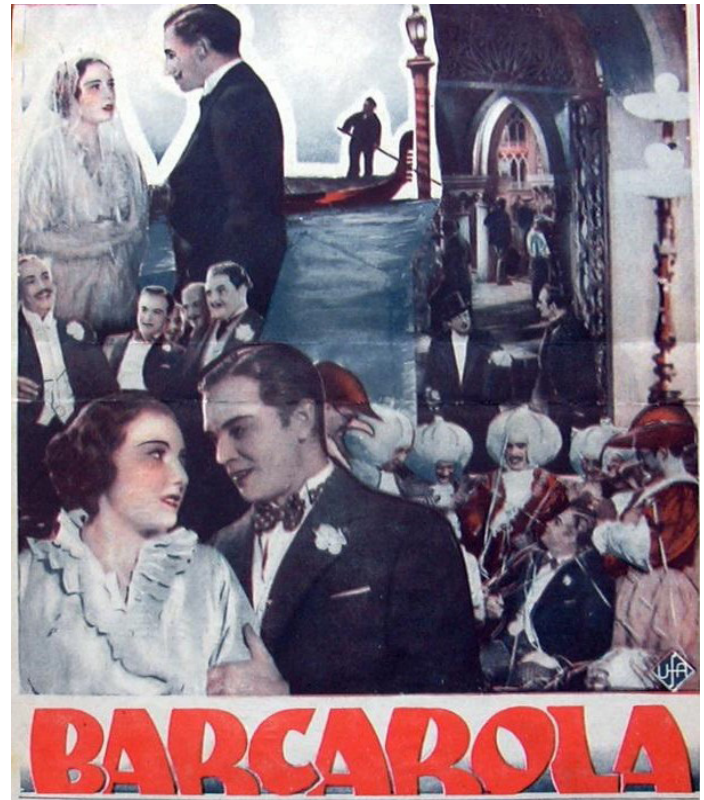

Cartel de Barcarole (Gerhard Lamprecht, 1935). «bom amigo»— acabó con un decreto del gobierno brasilero en 1938, que prohibió «cualquier actividad de naturaleza política ni inmiscuirse, directa o indirectamente, en los negocios públicos del país $»^{49}$.

La historia de la distribución de las películas de la Ufa -o de la Ufa- en Brasil es casi tan antigua como la propia $\mathrm{Ufa}^{50}$. La red brasileña de la Ufa consistía esencialmente en cuatro nombres: en la capital, Río de Janeiro, fueron Tibor Rombauer y Luiz Grentener. Quienes actuaron en São Paulo fueron Gustavo Zieglitz y Ugo Sorrentino, propietario de Art Films. Otro socio para Brasil y otros países como Bolivia, Chile y Perú (cuyo papel aún no está claro hoy en día) fue Rudolph Karstadt AG, de Hamburgo $^{51}$. En febrero de 1928, la junta directiva de la Ufa informó que se pretendía conceder la licencia de Brasil a Karstadt por veinticuatro películas de la temporada 1926/27, diecinueve de la producción de 1927/28, cinco películas antiguas y cinco películas culturales. La empresa Karstadt es una de las más ricas por tradición en la historia del comercio minorista en Alemania y es conocida, en primera instancia, por sus almacenes. Su actividad en el sector cinematográfico es un capítulo desconocido en la historia de la empresa. Karstadt recibiría la única licencia para Brasil para la temporada 1928/2952. Probablemente, el trato no se produjo porque la Ufa ya tenía para ese entonces socios cinematográficos locales experimentados.

De los cuatro contactos brasileños arriba mencionados - Rombauer, Grentener, Zieglitz y Sorrentino - fue Rombauer el primer empresario con quien la Ufa tuvo contratos. Los documentos de la Ufa reportan las ventas de veinte películas a Rombauer en $1919^{53}$. Al final de ese año, Rombauer publicó en un anuncio publicitario en el Correio da Manhã de Río que la empresa iba a presentar las últimas novedades del cine alemán ${ }^{54}$, y, en mayo de 1920, el diario informó sobre la nueva compra de películas alemanas por parte del empresario ${ }^{55}$. Con agencias en los estados de São Paulo, Bahía y al noreste de Brasil, Rombauer y la Ufa tuvieron una primera red de distribución en funcionamiento en el país.

[39] «Das Kino in Südamerika» (Der Film, $\mathrm{n}^{\circ}$ 48, 27 de noviembre de 1920), pp. 30-31.

[40] $N$ del E. Estrenada en España como Barcarola.

[41] N. del E. Estrenada en España como Comedia trágica.

[42] Reichsfilmkammer Hauptabteilung IV, Abtlg. 1 Fachgruppe Filmproduktion, Rundschreiben Betr. Deutsche Filme in Argentinien, 27 de febrero de 1936 , BArch, R 109-I/5430.

[43] Gesamtverband der Filmherstellung und Filmverwertung e.V an Ufa, 27 de junio de 1935, BArch, 109-I/5379; Correspondencia, 12 de junio de 1934, GIV f25 Schubert Chor/ 1929(1011), Arquivo do Instituto Martius-Staden, São Paulo, Brasil.

[44] Vorstandssitzung, 21 de diciembre de 1939, BArch, R 109-I/5430.

[45] «Imigração alemã no Brasil» Instituto Brasileiro de Geografia e Estatistica - IBGE $<$ https://brasil500anos.ibge.gov.br/ territorio-brasileiro-e-povoamento/ alemaes.html.25> (05/05/20)

[46] Luiz Alberto Moniz-Bandeira, Wachstumsmarkt Brasilien. Der deutsche Wirtschafts und Handelsbeitrag in Geschichte und Gegenwart. 2nd edition (Wiesbaden Springer Gabler, 2013), p. 15. 


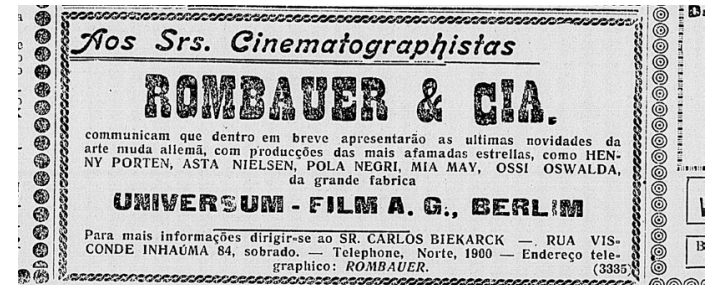

Anuncio publicitario de la empresa Rombauer \& Cia sobre la compra de películas alemanas (Correio da Manhã, 13 de deciembre 1919), p. 16.

[47] Fábio Koifman, «O governo Vargas e a política externa brasileira (1930-1945)», en Jorge Ferreira y Lucília de Almeida Neves Delgado (Org.), O Brasil Republicano. O tempo do nacional-estatismo: do início da década de 1930 ao apogeu do Estado Novo: Segunda República (1930-1945) (Rio de Janeiro, Civilização Brasileira, 2019).

[48] «Qualquer atividade de natureza política nem imiscuir-se, direta ou indiretamente, nos negócios públicos do país», Cláudio Aguiar Almeida, «O cinema brasileiro no Estado Novo: o diálogo com Itália, Alemanha e URSS» (Revista de Sociologia y Política, $\mathrm{n}^{\circ} 12,1999$ ), pp. 121-129. (Traducción de los editores)

[49] Koifman, «O governo Vargas».

[50] Wolfgang Fuhrmann, «A Ufa no Brasil: cinemas, empresários, e audiências» en Anais do Textos Completos do XXII Encontro da SOCINE 2018 (São Paulo, Socine, 1084-1089).

[51] Correspondencia, Departamento de comercio exterior (Auslandsabteilung), 16 de febrero de 1926, BArch, R 109-I/5434.

[52] Vorstandssitzung, 3 de febrero de 1928, BArch, R 109-I/1026b.

[53] BArch, R 109-I/644.

[54] Anuncio publicitario (Correio da Manhã, 13 de diciembre de 1919), p.16.

[55] «Mascara Sinistra. Antonio Moreneo-Carol Holloway») (Correio da Manhã, 16 de mayo de 1920), p. 16.

[56] Anuncio publicitario (Correio da Manhã, 4 de enero de 1922), p.12.

[57] Anuncio publicitario (Lichtbild-Bühne, n. $^{\circ} 11,11$ de marzo de 19,22), p 61.

Las películas de Rombauer y la Ufa pronto se hicieron famosas en la capital brasileña. En 1922, fue confirmado oficialmente que las películas de Rombauer ocuparon el segundo lugar en la capital brasilera después de las películas americanas $^{56}$.

Rombauer adquirió en 1921 el tradicional Cine Palais de la Avenida Tibor Rombauer ${ }^{63}$.

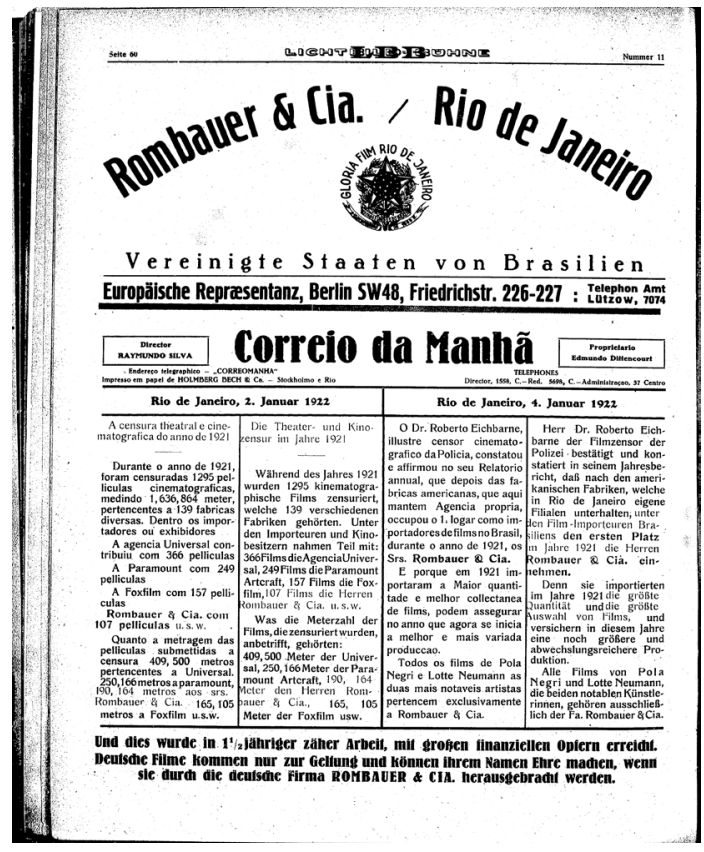
Río Branco, con el fin de ofrecer las producciones de la Ufa en un lugar de proyección permanente en la capital. En los años siguientes, Rombauer compró dos cines más en la ciudad: el Cine América y el Cine Americano ${ }^{57}$. Es muy probable que la rápida expansión de su compañía por sus nuevos cines haya llevado a Rombauer a tener que declararse, ya en 1923, en bancarrota. El Cine Palais fue subastado en 1926 y quedó en la memoria de muchos habitantes de Río de Janeiro como el cine que trajo las películas alemanas a la capital ${ }^{58}$.

Rombauer, como lo harían más adelante Luiz Grentener y Ugo Sorrentino, viajó personalmente a Berlín para cerrar contratos y comprar películas. Durante su viaje a Alemania en 1929, Luiz Grentener escribió para una revista brasileña un informe sobre su visita a los estudios de la Ufa en Babelsberg ${ }^{59}$. Ya un año antes, la revista de cine A Scena Muda había publicado un reportaje sobre la visita del equipo de redacción a la Ufa ${ }^{60}$. Aunque la Ufa perdió con Rombauer a un importante contacto en la capital, Luiz Grentener se convirtió en el nuevo socio de la Ufa en Brasil.

El papel que jugó Grentener en el negocio del cine en Brasil antes de 1926 no es claro. Está documentado que un tal Louis Grentner, de la productora vienesa Pax Film, estuvo activo en Río de Janeiro en diciembre de 1920 para proyectar películas médicas en el cine Pathé ${ }^{1}$. Un contacto entre Grentener y Rombauer sería obvio, así como el hecho de que Grentener adaptó fonéticamente su nombre para su posterior estancia en Brasil, una práctica común entre los inmigrantes. A finales de 1922, el diario Berliner Börsenzeitung informó en una corta nota sobre un cambio en la dirección de la empresa de Rombauer en Berlín ${ }^{62}$. Durante un mes, Luiz Grentener fue el gerente de la sucursal de Rombauer, pero un mes después ya había sido sustituido por 
Desde 1926, Grentener se convirtió en representante general de la Ufa en Brasil con su compañía Urania. Durante los años siguientes usó el eslogan: «Ufaos films que asombraram o mundo» para sus anuncios ${ }^{64}$ Mientras Grentener expandía su influencia y reputación en Río, Gustavo Emilio Augusto Zieglitz se convirtió en el punto de contacto para las producciones de Ufa en São Paulo.

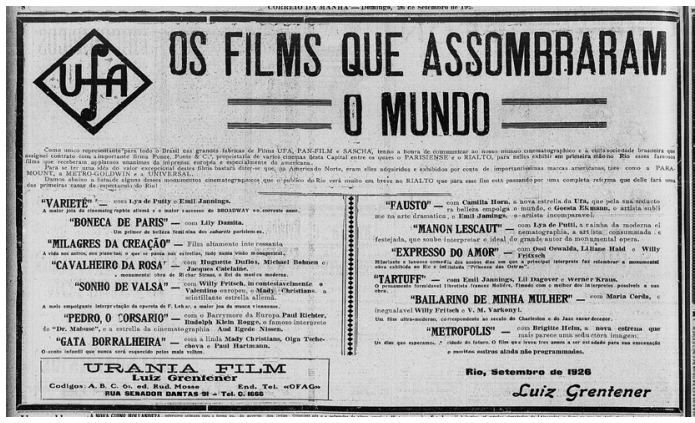

Anuncio publicitario de Luiz Grentener (Correio da Manhã, no. 9719, 26 de septiembre 1926), p.8

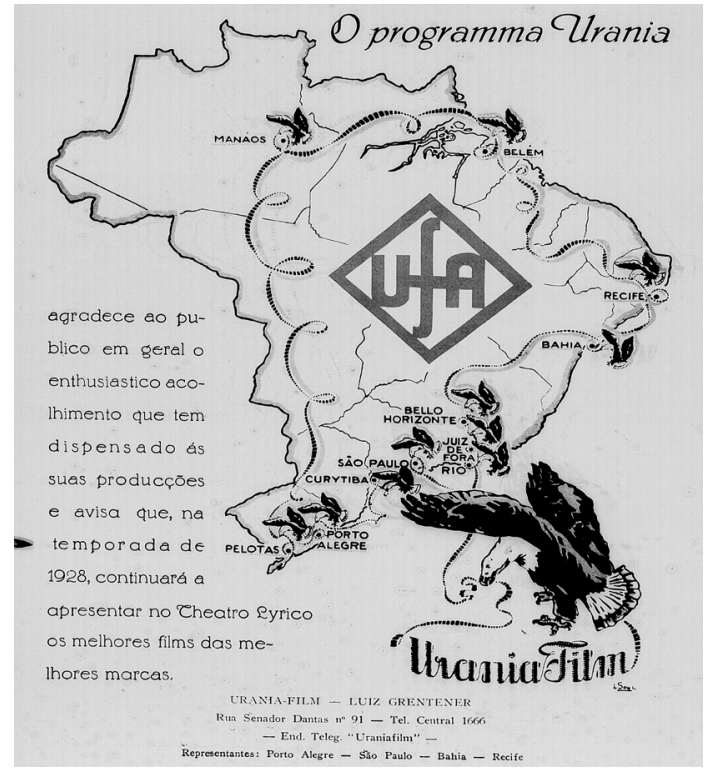

Anuncio publicitario, Grentener y la Ufa en Brasil (Cinearte, Album 1928), p. 1 으
Zieglitz comenzó el negocio del cine como empleado de Francisco Serrador, una gran empresa de cine, antes de cambiarse a la compañía francesa Pathé Frères ${ }^{65}$. Como representante de Tibor Rombauer en São Paulo, se convirtió más tarde en el representante de Luiz Grentener de la Urania en la ciudad.

Tanto Grentener como Zieglitz utilizaron el símbolo de la Ufa en sus anuncios y fueron fundamentales para consolidar a la Ufa como una marca de calidad en Brasil desde mediados de los años veinte. Lo mismo que se confirmó con lo observado en Argentina gracias al trabajo de Juan Probst. En diciembre de 1929, Grentener adquirió la concesión del cine Pedro II de São Paulo, y, dos años antes, en 1927, Zieglitz se hizo cargo del Colyseu Paulista. Sobre la entrada del edificio colgaba, en gran formato, el logotipo de la Ufa que invitaba a la gente a ir al cine, y, el día de su reapertura, fue presentada una película de la Ufa.
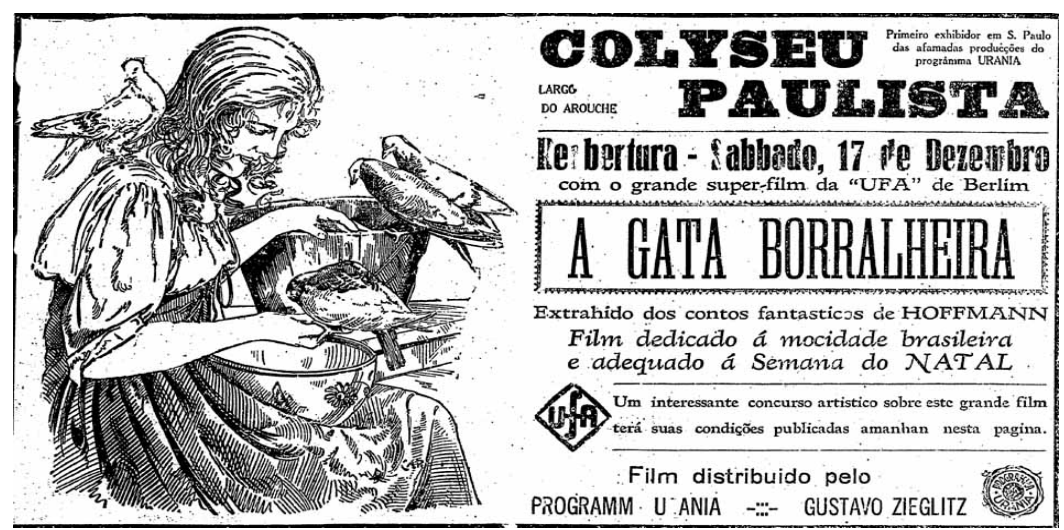

Anuncio publicitario para la reapertura del Colyseu Paulista, A Gata borralheira (Der verlorene Schuh, Ludwig Berger, 1923) (O Estado de S. Paulo 14 de diciembre de 1927), p. 17
[58] Varias Notas, «O Cine Palais desapparece» (Correio da Manhã, $3.12 .1926)$

[59] «Luiz Grentener e sua viagem a Alemanha» (Frou-Frou, augusto, 1929)

[60] «A Scena Muda, na "Ufa" em Berlim» (A Scena Muda, n. ${ }^{\circ}$ 381, 12 de julio de 1928).

[61] No mundo da Tela. « No cinema de Pathé» (Correio da Manhã, 28 de diciembre de 1920), p.5.

[62] «Rombauer \& Co. Gesellschaft mit beschränkter Haftung» (Berliner Börsenzeitung, $\mathrm{n}^{\circ}$ 498, 4 de noviembre 1922), p.4.

[63] «Rombauer \& Co. Gesellschaft mit beschränkter Haftung».

[64] Anuncio publicitario (Correio da Manhã, 26 de septiembre de 1926), p.8.

[65] Rafael de Luna Freire, "Gustavo Zieglitz e a Empresa Cinematográfica Pathé», Caderno de Resumos, III. Jornada de estúdios em história do cinema brasileiro, III. Fórum de Pesquisas em História do Cinema Brasileiro (Universidade Federal de São Carlos, 2019) 


\section{La calidad de las películas con el sello Ufa}

Hasta la segunda mitad de los años treinta, la Ufa fue, desde entonces, una experiencia cinematográfica especial. Si se leen las críticas de los largometrajes alemanes en Brasil, las películas alemanas se consideraban inicialmente como un cambio bien recibido y un desafío al cine dominante de Hollywood. Solo en una etapa tardía se les asoció con la propaganda fascista. Como escribe el historiador brasileño Flavio Bugatti Isolan, las producciones de la Ufa debían su popularidad en el sur de Brasil al alto nivel técnico, que se expresaba sobre todo en la puesta en escena de la luz, la música y el trabajo de cámara, y que atraían repetidamente a la prensa con elogios y superlativos. Metrópolis (Metropolis, Fritz Lang, 1925/26), Fausto (Faust, Friedrich Wilhelm Murnau,1925/26), Varieté (Ewald A. Dupont, 1925) o El sueño de un vals, de Ludwig Berger, fueron efusivamente celebradas como «milagros de la moderna cinematografía» y «obra brillante de puro arte» ${ }^{66}$.

La observación de Isolan para el sur del país, donde el porcentaje de la población de ascendencia alemana era más alto, parece haberse aplicado también a la capital Río de Janeiro. En una entrevista con el Diario Carioca en marzo de 1929, Grentener explicó que el éxito de las películas de la Ufa se debía a la atención al detalle y la finura técnica que distinguía a las producciones alemanas ${ }^{67}$.

Cuando los nazis llegaron al poder, la percepción del cine alemán en la prensa brasileña cambió, aunque no desde una perspectiva crítica de la política de Alemania. Como Isolan anota, si bien el público brasileño apreciaba el cine de Weimar porque ofrecía temas - lascivia y transgresiones morales, por ejemplo- que Hollywood no podía presentar por causa de sus estrictas normas de producción, era el carácter educativo de las películas lo que representaba a la nueva Alemania, que aun así se producían a un alto nivel artístico ${ }^{68}$.

La reputación de la Ufa en Brasil fue aprovechada por los cines de diferentes maneras. Para su inauguración, los dos cines de São Paulo eligieron producciones de la Ufa. El Cine Selecto mostró Maravillas del universo (Wunder der Schöpfung, Hanns Walter Kornblum, Johannes Meyer y Rudolf Biebrach, 1924/25) ${ }^{69}$ y, el Cine Imperio, la película The Blackguard/Die Prinzessin und der Geiger (Graham Cutts, 1927)70.

[66] Flaviano Isolan Bugatti, Das páginas à tela, p. 89.

[67] «A temporada cinematográfica. O que nos promette as grandes agencias» (Diario Carioca, n. $^{\circ}$ 193, 1 de marzo de 1929), p. 5.

[68] Flaviano Isolan Bugatti, Das páginas à tela, pp. 93-95.

[69] Anuncio publicitario ( $O E S$ tado de S. Paulo, 30 de enero de 1927), p.22.

[70] Anuncio publicitário ( $O$ Estado de S. Paulo, 11 de junio de 1927), p. $17 .^{\circ}$

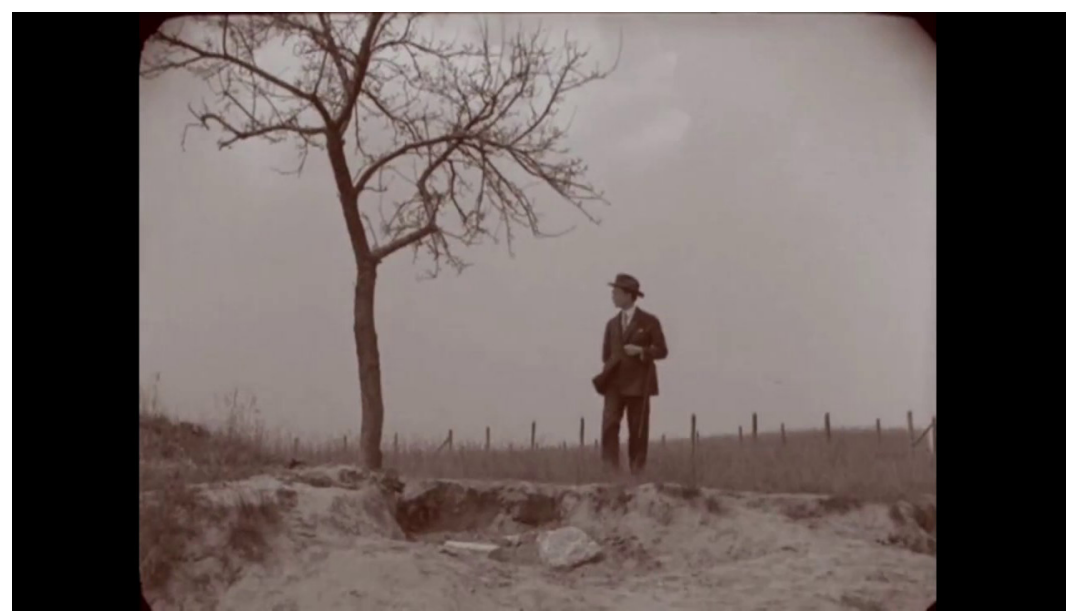

Fotograma de Maravillas del universo (Wunder der Schöpfung, Hanns Walter Kornblum, Johannes Meyer y Rudolf Biebrach, 1924/25) 
Mientras la prensa brasileña celebraba las películas de la Ufa por sus características artísticas, la sede de la compañía en Berlín estaba menos eufórica por el rendimiento de sus producciones y buscaba el concepto de mercadeo más adecuado para el país. Según los informes de la junta directiva de la Ufa, el mercado brasilero era difícil de evaluar. Contrariamente al éxito esperado de Concierto en la corte (Das Hofkonzert, Detlef Sierck, 1936), deseando que fuese similar al obtenido en otros países, la película no logró alcanzarlo a pesar de la popularidad de la actriz Martha Eggerth en Brasil. Películas como La novena sinfonía (Schlussakkord, Detlef Sierck, 1936) y El pobre estudiante (Der Bettelstudent, Georg Jacoby, 1936) demostraron también ser solo éxitos parciales, así como Willy Birgel, una superestrella de la Ufa en Alemania, pero que no gozaba de gran popularidad en Brasil ${ }^{71}$.

Algunos propietarios de cine brasileños adoptaron las películas de la Ufa de una manera muy particular ${ }^{72}$. En abril de 1935, la sede de la Ufa en Berlín recibió una carta indignada del «austriaco de pensamiento y alemán de sentimiento» Eugenio de Félix, quien vivía en Brasil y quiso llamar la atención sobre la escandalosa situación de algunos cines brasileños. De profesión empresario y productor de películas de naturaleza, de Félix informó sobre los cines en São Paulo y Río de Janeiro que proyectaban películas alemanas, todos los días desde las dos de la tarde hasta la medianoche, en la categoría «solo para hombres». Según de Félix, el dueño de los cines compró películas de la distribuidora brasileña Urania, Luiz Grentener, para que después se trabajaran escenas pornográficas ${ }^{73}$. La Ufa contactó a Grentener y Rudolf Karstadt AG para aclarar el origen de las películas. El resultado del incidente aún no es conocido.

La situación comercial de la Ufa en Brasil cambió durante los años treinta. Grentener y Zieglitz fueron sustituidos en gran parte por Ugo Sorrentino quien, desde 1932, se convirtió en el representante de ventas más importante de la Ufa con su compañía Art Films ${ }^{74}$. Sorrentino fundó Art Films en diciembre de 1931 con el objetivo de mostrar películas europeas en las pantallas brasileñas ${ }^{75}$. En 1932, se aseguró sus primeras copias de las producciones sonoras de la $\mathrm{Ufa}^{76} \mathrm{y}$ organizó la distribución por contratos con los grandes exhibidores en Brasil: Luiz Severiano Ribeiro y Francisco Serrador ${ }^{77}$. De esta manera, Art Films de Sorrentino estuvo representada en un total de 420 ciudades y tenía 771 salas de proyección. Otro paso importante hacia una mayor visibilidad de la Ufa en el país fue la oferta de Sorrentino de abrir un Ufa Palácio en el corazón de São Paulo.

\section{El Ufa Palácio en São Paulo}

Brasil fue el primer país del continente sudamericano que tuvo su propio Ufa-Palast, el Ufa Palácio. El 13 de noviembre de 1936, el cine, con más de tres mil sillas, abrió sus puertas en la entonces principal arteria de la ciudad de São Paulo, la Avenida São João. Entre los invitados estuvieron representantes de otras empresas cinematográficas de la ciudad, autoridades locales y del Estado de São Paulo. Desde Alemania, Wilhelm Meydam, jefe de distribución de la Ufa y Berthold von Theobald, del departamento de asuntos exteriores de la Ufa, vinieron a São Paulo.

El Ufa Palácio se presentó como uno de los cines más modernos de su época en cuanto a tecnología y arquitectura. El arquitecto fue uno de los más destacados del modernismo brasileño: Rino Levi ${ }^{78}$. En solo seis meses, Levi construyó el Ufa Palácio con una acústica completamente novedosa y una iluminación indirecta. Según se publicitó,
[71] Vorstandssitzung, 28 de julio de 1937, BArch, R 109-I/1032b.

[72] Wolfgang Fuhrmann, «Transnational Film History? Um Cinema Teuto-Brasileiro», en Anke Finger, Gabi Kathöfer y Christopher Larkosh (eds.), KulturConfusão - On German-Brazilian Interculturalities (Berlin; Boston, De Gruyter, 2015), p.190.

[73] Correspondencia, 20 de abril de 1935, BArch, R 109 I/5379.

[74] Flaviano Isolan Bugatti, Filmabsatzgebiet Brasilien, p. 35-37.

[75] Según Máximo Barro, Grentener cerró Urania en 1933, lo que favoreció a Sorrentino para colaborar con la Ufa. Maximo Barro, Participação italiana no cinema brasileiro (São Paulo, SESI- SP editora, 2017), sin número de página. Otro factor que pudiera dar un papel importante era un conflicto jurídico sobre películas entre Grentener y el Rudolph Karstadt AG, entre 1932 hasta 1935.

[76] «Alguns momentos a bordo do "Dulio", hontem chegado de Genova» (Correio da Manhã, n. ${ }^{\circ}$ 1457, 19 de abril 1932), p.3.

[77] Flaviano Isolan Bugatti, Filmabsatzgebiet Brasilien, p. 38.

[78] Paula Santoro Freire, «Da relacão das salas de cinema com o urbanismo moderno na construçao de uma centralidade metropolitana: A Cinelandia Paulistana». <https://www. academia.edu/12103273/A_rela $\% \mathrm{C} 3 \% \mathrm{~A} 7 \% \mathrm{C} 3 \% \mathrm{~A} 30$ das_salas_de_cinema_com_o_urbanismo_moderno_na_constru\%C3\%A $\overline{7} \% \mathrm{C} 3 \% \mathrm{~A} 3 \overline{\mathrm{o}} \_$de_uma_centralidade_metropolitana_a_Cinel\%C3\%A2ndia_Paulistana> $(05 / 05 / 20)$. 


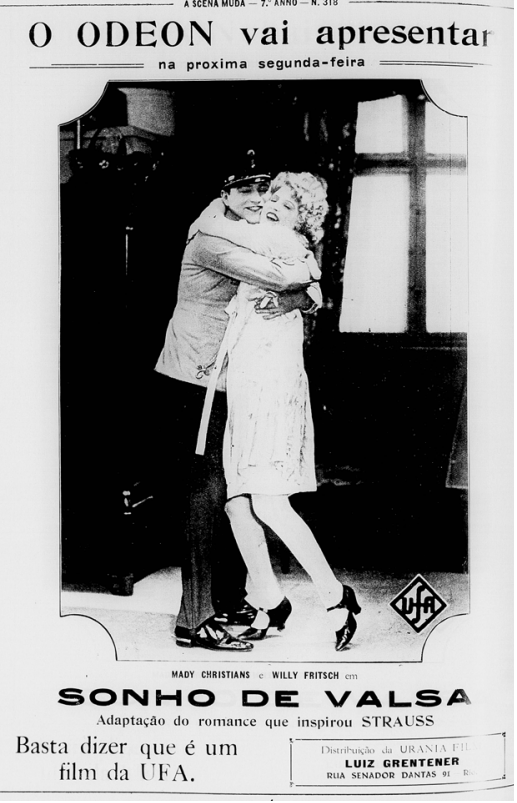

Anuncio publicitario, El sueño de un vals (Ein Walzertraum, Ludwig Berger, 1925) (A Scena Muda, no. 318,28 de abril de 1927), p.1.

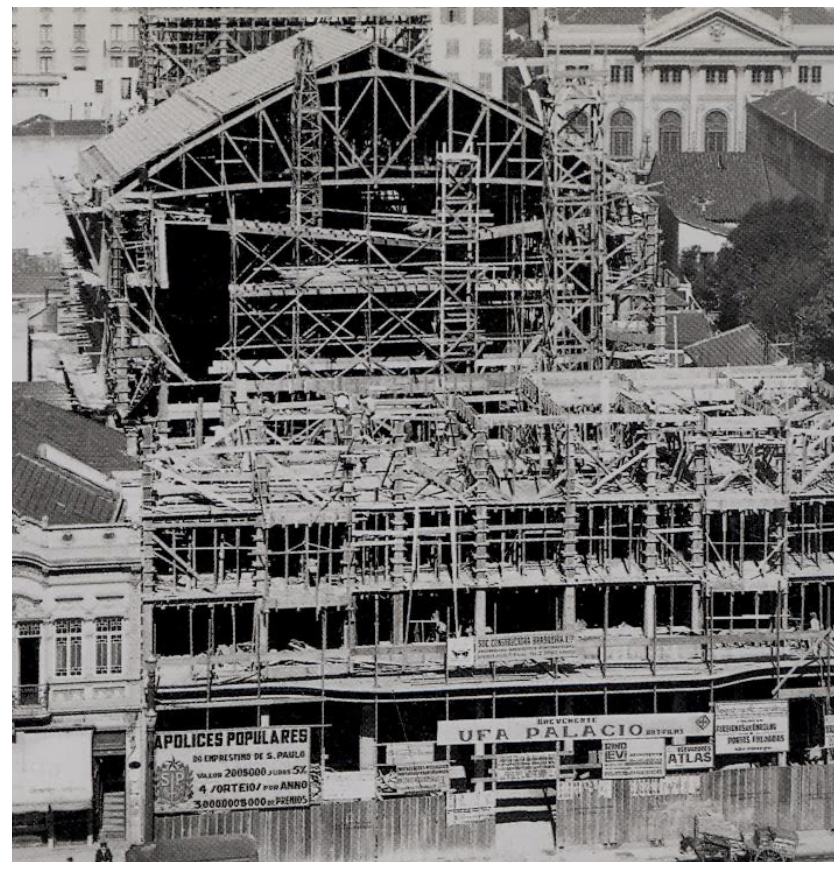

El Ufa Palácio en São Paulo en construcción en 1936, Fuente: http://saopaulo-40s-50s-60s.blogspot.com/2013/11/cine-art-palacio.html
[79] Anuncio publicitario (Correio Paulistano, 13 de noviembre de 1936), p.8.

[80] «"Boccaccio", um grande espectaculo será o filme do primeiro programa do novo cinema» (Correio de São Paulo, $\mathrm{n}^{\circ} 1348,9$ de noviembre de 1936).

[81] «Ufa Palácio inaugurar-se-a na proxima quinte-feira, dia 12 do corente, a nova e majestosa casa de espectaculos da avenida S João» (Correio Paulistano, $\mathrm{n}^{\circ}$ 24740, 8 de noviembre, 1936).

[82] «Kinoschau» (Deutsche Zeitung, 4 de noviembre de 1936), p.7.

[83] «Eröffnung des Ufa-Palastes» (Deutsche Zeitung, 12 de noviembre de 1936). el Palácio fue el cine del que la ciudad había carecido anteriormente ${ }^{79}$ y solo comparable con salas en los Estados Unidos y Europa ${ }^{80}$. Con el Palácio, São Paulo estaba al mismo nivel de las capitales del mundo ${ }^{81}$. El decorado interior fue elogiado por la prensa como un monumento a la amistad y al intercambio cultural germano-brasileños ${ }^{82}$.

La noche del estreno fue un único acierto, tanto para la Ufa como para su socio brasileño. Para iniciar la velada, la orquesta del Centro Musical de São Paulo tocó la obertura de la ópera Salvator Rosa, del compositor brasileño Antonio Carlos Gomes. Como una especie de anticipo a la película principal, fue interpretada la sinfonía de la opereta Boccaccio. El programa cinematográfico del estreno consistió en dos cortometrajes sonoros: el cortometraje brasileño Grupo Escolar de Butantã, sobre el famoso instituto de investigación de la ciudad, y la película cultural alemana Briefe fliegen über den Ozean [Cartas voam sobro o Oceano] (Fritz Kallab, 1935), sobre la correspondencia entre Alemania y Brasil/Argentina, que puso al público en el estado de ánimo adecuado para la película principal. Un noticiero de la Ufa completó el programa de apoyo cinematográfico ${ }^{83}$.

El periódico local Correio Paulistano había anunciado una votación especial, con la cual el público local decidió la película que debía ser mostrada en la inauguración del Palácio. La ganadora fue la adaptación de la opereta Bocaccio (Boccaccio) de Herbert Maisch (1936), con las conocidas estrellas de la Ufa Willy Fritsch, Heli Finkenzeller y Paul Kemp.

Con gran pasión, O Estado de S. Paulo elogió al Ufa Palácio:

el cine más moderno de la ciudad. «Moderno», aquí, en este caso, tiene un sentido total: quiere decir grande como São Paulo, bueno como São Paulo, útil como São 
Paulo, sobrio como São Paulo, acogedor como São Paulo, bonito como São Paulo. Es el cine 'para' São Paulo ${ }^{84}$.

La apertura del Ufa Palácio fue el punto culminante de la historia de éxito de la Ufa en Brasil. El cinema no costó ni un centavo, porque fue financiado solo por Sorrentino. Antes, Sorrentino habría solicitado a la Ufa, en diciembre de 1935, el uso del nombre para el nuevo palacio del cine. Con la apertura de un cine bajo su nombre, la Ufa siguió a la Paramount, la cual ya tenía un cine con su nombre, y se adelantó a la Metro-Goldwyn-Mayer, que no abrió un cine en la ciudad hasta 1938.

\section{Su propia cadena de salas de cine para Brasil}

El Ufa Palácio se supuso que marcaría el comienzo de una nueva era de la Ufa en Brasil, pero marcó el comienzo del fin para la compañía en el país. La petición de Sorrentino de nombrar el nuevo palacio del cine como Ufa respondió a una estrategia publicitaria que la junta directiva de la Ufa discutió una y otra vez: la participación en cines o la gestión de cines propios en el extranjero transatlántico. Ya en junio de 1928, la junta directiva de la Ufa había recibido una solicitud para participar en la renovación y el rediseño del Teatro Lyrico de Río de Janeiro, entre otros con la empresa Karstadt, con el fin de obtener una mejor posición en el mercado de América Latina. Ufa aceptó la solicitud, retirada unas semanas después ${ }^{85}$.

La cuestión de los teatros propios o el acceso privilegiado a teatros extranjeros seguía siendo un tema vigente en el interior de la Ufa. En 1935, poco antes de la solicitud de Sorrentino a la Ufa, la junta directiva de la Ufa discutió si sería conveniente «la participación de un tercero en capitales importantes como Londres, Viena, Nueva York, etc. ${ }^{86}$ Wilhelm Meydam, jefe de distribución de la Ufa, explicó seguidamente que los productos alemanes aptos para el mercado exterior no estaban disponibles en cantidades suficientes. Por lo tanto, no se aprobó una resolución sobre este punto. La proyección solo de las producciones de la Ufa en un cine extranjero siguió siendo problemática también en Brasil. A partir de marzo de 1937, las producciones de las grandes compañías cinematográficas norteamericanas y las películas francesas también se exhibieron en el Ufa Palácio. Sin embargo, el proyecto de tener una red propia de cines seguía en pie, no solo simplemente para darles nombre, como en São Paulo, sino de forma independiente y autónoma. Ante los desacuerdos sobre la gestión de Sorrentino, la Ufa planeó fundar sus propias empresas con Sorrentino a partir de 1938: la Ufa-ArtFilm Limitada, en Río de Janeiro, con un capital social del 51\%; y la Ufa -Palácios do Brasil Limitada, en Río de Janeiro, con un capital social del $66 \%{ }^{87}$.

Con la realización de estos proyectos en la mira, Berthold von Theobald viajó a Río de Janeiro en abril de 1938 para fundar las empresas. Los primeros Ufa Palácios se establecieron en Río de Janeiro, Campinas, en el Estado Federal de São Paulo, y en Recife, al noreste del país, en el Estado Federal de Pernambuco. El arquitecto Rino Levi, quien al menos para Recife ya tenía los planos listos en su cajón, fue de nuevo encargado.

El nuevo modo de colaboración con Sorrentino le permitió a la Ufa tener más control sobre la distribución de sus películas, como reacción a los problemas estructurales que la Ufa encontró en Brasil. La Ufa expresó su desazón con la organización de la empresa e insinuó, entre líneas, un sistema de nepotismo. Varios miembros de la familia Sorrentino ocuparon posiciones claves y, en dos casos, Sorrentino pagó altos
[84] «O mais moderno cinema da cidade. 'Moderno', aqui, neste caso, tem um sentido total: quer dizer grande com São Paulo, bom como São Paulo, útil como São Paulo, discreta como São Paulo, acolhedor como São Paulo, lindo como São Paulo. É o cinema 'para' São Paulo», «Cinematographos. O "Ufa Palácio"» (O Estado de S. Paulo, 12 de noviembre de 1936), p.6. (Traducción de los editores)

[85] Vorstandssitzung, 18 de junio de 1928 y 22 de junio de 1928, BArch, R 109 I/1026b. La junta directiva de la Ufa discutió una coproducción entre Brasil y Alemania en diciembre de 1927. En caso de su realización, la Ufa quería financiar la producción con 150 - 200.000 Reichsmark. Vorstandssitzung, 23 de diciembre de 1927, BArch, R 109 I/1026b.

[86] Vorstandssitzung, 12 de marzo de 1935. BArch, R 109 $\mathrm{I} / 1026 \mathrm{~b}$.

[87] BArch, R 109-I/2909a, anexo. 
[88] BArch R 109-I/525, p 12.

[89] Correspondencia, Ufa an das Reichsministerium für Volksaufklärung und Propaganda, 8 de agosto de 1939, BArch, R 109. I/5430.

[90] Ibidem.

[91] Vertrag Winkelmann (contrato), 20 de diciembre de 1938, BArch, 109-I/5430.

[92] En agosto de 1945 está reportado que un señor Walter Winkelmann se suicidió en Río de Janeiro. «Atirou-se de 9 andar de edifício Brazilia» (Gazeta de Noticias, $\mathrm{n}^{\circ} 194,21$ de agosto de 1945), p 9.

[93] Abschrift zu 5856/13.3. Übersicht über die vom 1. Januar bis zum 31.Dezember 1939 vorgeführten Film, BArch, R 109-I/ 1611 ,

[94] Correspondencia, NSDAP, Leitung der Auslands-Organisation an Reichsministerium Volksaufklärung und Propaganda, 4 de junio de 1940. BArch, R 109-I/1611.

[95] Abschrift zu 5856/13.3. Übersicht über die vom 1. Januar bis zum 31. Dezember 1940 vorgeführten Film, BArch, R 109-I/ 1611.

[96] «S. Paulo comemora um regime de trabalho e prosperidade» (O Radical, n. ${ }^{\circ} 3437,9$ de noviembre de 1941), p. 6.

[97] «E façamos votos para que ele sobreviva, porque seria uma perda irreparável para o cinema, se este ficasse privado do talento de um cineasta como Willy», «Willy Forst» (A Scena Muda n. ${ }^{\circ}$ 19,8 de mayo de 1945), p.6. (Traducción de los editores) salarios a miembros de la familia que, en realidad, no colaboraron con la empresa. En sucursales de Sorrentino se trabajó sin control y con una contabilidad casi inexistente. Las películas estuvieron en las carteleras más tiempo del acordado y, a veces, el alquiler fue más bajo del que se había acordado ${ }^{88}$.

Adicionalmente, la Ufa notó un ambiente antialemán en el país. En agosto de 1939, Sorrentino reportó a la Ufa que debía editar varios noticiarios sonoros para el exterior (Auslandstonwochen), porque fueron abucheados por el público en su formato original. En aras de mantener la distribución y calmar las relaciones con los dueños de las salas de cine, Sorrentino decidió tomar esta medida ${ }^{89}$. Los acontecimientos políticos durante los meses siguientes arruinaron los planes de expansión de la Ufa en Brasil por un tiempo imprevisible.

\section{El fin de la Ufa en Brasil}

En agosto de 1939, Sorrentino informó a la Ufa que ya no trabajaría para ellos: la Ufa perdió de este modo a su cliente más importante en el país ${ }^{90}$. Desde ese año hasta 1941, por lo menos, el comerciante Walter Winkelmann representó a la Ufa en Brasi191. Winkelmann cambió de Warner Brothers Brasil a la Ufa y fue originariamente designado para encargarse del proyecto Ufa do Brasil. Sin embargo, se encargó de atender de ahí en adelante a Brasil, Argentina y casi todos los países de Suramérica y América Central ${ }^{92}$.

Durante 1939, solamente nueve títulos alemanes fueron proyectados en São Paulo $^{93}$. Al año siguiente, en una carta dirigida al Ministerio del Reich para la Ilustración Popular y Propaganda, un representante regional del Partido Nacionalsocialista Obrero Alemán advirtió que la industria cinematográfica alemana casi había desaparecido en São Paulo: «creo que se hayan proyectado aquí no más que cinco películas alemanas desde el comienzo de la guerra, aunque hubiera dos buenas entre las películas El soberano (Der Herrscher) y Heimat. ${ }^{94}$ Para el final del año, el número de películas alemanas proyectadas aumentó solo a doce ${ }^{95}$.

Un supuesto intento de golpe de estado de los integralistas de derecha contra el presidente Getulio Vargas y la campaña de nacionalización de Vargas dificultó las actividades comerciales de los inversionistas extranjeros. Unos meses después del estallido de la guerra, el Ufa Palácio fue rebautizado como Art Ufa Palácio y, en 1940, finalmente se llamó Art Palácio. La prensa de habla italiana de São Paulo lamentó el cambio de nombre y, solo unas semanas después, deseó que el cine recuperara pronto su antiguo nombre. Hasta finales de 1941, se mencionó Ufa Palácio en la prensa paulista como punto de orientación en la ciudad ${ }^{96}$.

Aunque las películas de la Ufa no se vieran más, las estrellas de la Ufa no fueron olvidadas. En mayo de 1945, la revista de cine brasileña $A$ Scena Muda informó sobre el presunto arresto de Willy [sic] Forst por la Gestapo y su envío a un campo de concentración cerca de Bremen. Refiriéndose a los muchos éxitos de Forst y a su última película Opereta (Operette, Willi Forst, Karl Hartl, 1940), la cual fue exhibida en Brasil, la revista comentó: «y esperemos que sobreviva, porque sería una pérdida irreparable para el cine, si fuese privado del talento de un cineasta como Willy ${ }^{97}$.

\section{Conclusión}

La atención hacia Brasil muestra que la Ufa planeó recuperar una medida que los estudios de Hollywood hubieran tomado años antes, a saber, sucursales locales que 
permitieron la investigación de los mercados nacionales de formas directa.

En los informes anuales de la Ufa, se quejaban repetidamente de la lentitud y la decepción de los negocios extranjeros que, si se examinan de cerca, eran en parte ocasionados por la misma Ufa. La correspondencia se refiere frecuentemente a la falta de presencia de la Ufa en los países ${ }^{98}$. Si la Ufa pudo contar con una audiencia regular en países con fuerte inmigración alemana, los países sin este grupo de audiencia dependían de una red de distribución fiable y funcional ${ }^{99}$. Según una carta dirigida a la Ufa que data de 1940, un tercero (Untervertreter) en Chile no podía conocer las preferencias del público peruano ${ }^{100}$. La evaluación de las audiencias o la observación del mercado eran importantes medidas para asegurar el éxito de una película. Las representaciones permanentes en los países proporcionaron información más fiable a largo plazo. Si un comprador se alejaba de la Ufa, el cine alemán ya no estaba presente en el país. Hasta los años cuarenta, con excepción de Brasil, no hay indicios de que se hayan discutido intensamente propuestas en la junta directiva de tener una representación permanente de la $\mathrm{Ufa}^{101}$.

Al contrario de la Ufa, las empresas de producción norteamericanas mantenían sus propias sucursales de alquiler y asumían todo el riesgo financiero. Su presencia también significó un acceso más directo al público nacional y una adaptación inmediata a la demanda ${ }^{102}$. En 1919, Fox tuvo representantes o sucursales en todos los países excepto Colombia ${ }^{103}$. Paramount Film abrió sus oficinas en Buenos Aires y Santiago de Chile en $1925^{104}$. En 1926, United Artists abrió su oficina en Río de Janeiro $^{105}$. En Colombia, todos los estudios de Hollywood tenían su propia oficina en el país hasta $1932^{106}$.

La Ufa siguió la estrategia de los estudios de Hollywood en su sistema de sucursales; pero, en contraste con sus «despiadados métodos americanos», la Ufa se basó en el amistoso «acuerdo con nuestro anterior cliente merecedor» para su experimento modelo en Brasi $1^{107}$. La Ufa à la Hollywood también pretendía incluir en el programa, además de las producciones alemanas, los llamados «internationale Schleppfilme», es decir, producciones de empresas extranjeras, con el fin de mantener la oferta amplia y atractiva. Brasil iba a desempeñar el papel de pionero para la Ufa en América Latina y, aunque el sistema de sucursales no surgió en ese momento, el mismo modelo se discutió para Argentina a partir de septiembre de $1938^{108}$. La difícil situación monetaria impidió la realización de este proyecto.

El creciente aislamiento político de Alemania al final de los años treinta y la sucesiva entrada de los países latinoamericanos en la Segunda Guerra Mundial del lado de los Aliados hicieron que las relaciones comerciales estables y continuas con los socios de América Latina fueran cada vez más difíciles y, en última instancia, imposibles. En mayo de 1941, un socio de Guatemala dibujó un cuadro pesimista de la situación para la Ufa: «Si incluso un cine de propiedad y bajo dirección alemanas se niega a mostrar ahora películas alemanas, se puede imaginar que por el momento no hay ni la más mínima posibilidad de mostrar aquí las producciones alemanas en los grandes cines de estreno» ${ }^{109}$.

La buena reputación de la cual gozó la Ufa en América Latina en los años treinta se perdió a principios de la década de 1940. Después de 1942, no hubo películas de la Ufa en Brasil, y lo mismo ocurrió en todos los demás países de América Latina.
[98] Filmgeschäft in Kolumbien. 29 de julio de 1939. BArch, R 109-I/ 1611 .

[99] Ibidem.

[100] Correspondencia, E. Grundmann (Lima, Peru) an einen «Freund», 27 de diciembre de 1940, BArch, 109-I/1611.

[101] La idea de adquirir un cinema para mostrar películas de la Ufa surgió para el mercado argentino en 1941. Notiz,10 junio de 1941, BArch, R 109-I/1611.

[102] NSDAP, Auslands-Organisation, Landesgruppe Peru an Deutsche Botschaft Lima, 31 de enero de 1939. BArch, R 109$\mathrm{I} / 1611$,

[103] Thompson, Exporting Entertainment, p. 72 .

[104] Thompson, Exporting Entertainment, p. 209.

[105] Pedro Butcher, «"Bravo, Sr. Baez!": O Brasil em The United Artists Around the World» en Anais de Textos Completos do XXIII Encontro SOCINE (São Paulo, SOCINE), p.1015.

[106] Leidy Paola Bolaños Florido, Cine silente, p. 75.

[107] Correspondencia, Ufa an Deutsche Gesandtschaft in Lima, 26 de octubre de 1937, BArch, R $109-\mathrm{I} / 5430$.

[108] Gedächtnisvermerk, Argentinien-Besprechung, 29 de septiembre de 1938, BArch, R $109-\mathrm{I} / 5430$.

[109] Correspondencia, Diestel, Hastedt \& Co, Guatemala, 7 de majo 1941, BArch, R 109-I/1611. 


\section{FUENTES PRIMARIAS}

Documentos de la Ufa, Signatura: R 109-I, Bundesarchiv Berlin (BArch), Alemania. Arquivo do Instituto Martius-Staden, São Paulo, Brasil.

Hemeroteca Digital Brasileira <https://bndigital.bn.gov.br/hemeroteca-digital/>

\section{FUENTES HEMEROGRÁFICAS}

\section{A Scena Muda}

«A Scena Muda, na "Ufa” em Berlim» (n. ${ }^{\circ} 381,12$ de julio de 1928), pp. 5-7, 31. «Willy Forst» (n. ${ }^{\circ} 19,8$ de mayo de 1945), p.6.

\section{Berliner Börsenzeitung}

Rombauer \& Co. Gesellschaft mit beschränkter Haftung (n. ${ }^{\circ} 498,4$ de noviembre 1922), p.4.

Rombauer \& Co. Gesellschaft mit beschränkter Haftung (n. ${ }^{\circ}$ 580, 23 de deciembre 1922), p.12.

\section{Correio da Manhã}

No mundo da Tela, «No cinema de Pathé» (n. ${ }^{\circ} 7972,28$ de diciembre de 1920), p.5. Anuncio publicitario (n. ${ }^{\circ} 8432,4$ de enero de 1922), p.12.

Varias Notas, «O Cine Palais desapparece» (n. ${ }^{\circ} 9777,3$ de diciembre de 1926), p.6. «Alguns momentos a bordo do "Dulio", hontem chegado de Genova» (n. ${ }^{\circ}$ 1457, 19 de abril 1932), p.3.

Anuncio publicitario (n. ${ }^{\circ} 9719,26$ de septiembre de 1926), p.8.

Anuncio publicitario (n. ${ }^{\circ} 7599,13$ de diciembre de 1919), p.16.

(n. ${ }^{\circ} 7446,16$ de mayo de 1920), p. 16.

\section{Correio de São Paulo}

«"Boccaccio", um grande espectaculo será o filme do primeiro programa do novo cinema» (n. ${ }^{\circ} 1348,9$ de noviembre de 1936), p. 8.

\section{Correio Paulistano}

«Ufa Palácio inaugurar-se-a na proxima quinte-feira, dia 12 do corente, a nova e majestosa casa de espectaculos da avenida S João» (n. ${ }^{\circ} 24740,8$ de noviembre de 1936), p. 12.

Anuncio publicitario (n. ${ }^{\circ} 24744,13$ de noviembre de 1936), p.8.

\section{Deutsche Zeitung}

«Eröffnung des Ufa-Palastes» (12 de noviembre de 1936), p. .

«Kinoschau» (4 de noviembre de 1936), p.7.

Der Film

«Das Kino in Südamerika» (n. ${ }^{\circ}$ 48, 27 de noviembre de 1920), pp. 30-31.

\section{Diario Carioca}


«A temporada cinematográfica. O que nos promette as grandes agencias» (n. ${ }^{\circ}$ 193, 1 de marzo de 1929), p. 5.

\section{Excelsior}

Anuncio publicitario (n ${ }^{\circ} .598,26$ de agosto de 1925).

Anuncio publicitario (nº.640, 18 de junio de 1926).

\section{Film Kurier}

Ugo Sorrentino, «200 brasilianische Kinos für den deutschen Film» (28 de julio de 1934).

\section{Frou-Frou}

«Luiz Grentener e sua viagem a Alemanha» (agosto, 1929), pp. 16-17.

\section{Gazeta de Noticias}

«Atirou-se de 9 andar de edifício Brazilia» (n. ${ }^{\circ}$ 194, 21 de agosto de 1945), p. 9.

\section{Lichtbild-Bühne}

Anuncio publicitario (n. ${ }^{\circ} 11,11$ de marzo de 1922), p.61.

O Estado de S. Paulo

«Cinematographos. O "Ufa Palacio"» (12 de noviembre de 1936), p.6.

Anuncio publicitario (30 de enero de 1927), p.22.

Anuncio publicitario (11 de junio de 1927), p. 17.

\section{O Radical}

«S. Paulo comemora um regime de trabalho e prosperidade» (n. ${ }^{\circ} 3437,9$ de noviembre de 1941), p. 6.

\section{BIBLIOGRAFIA}

AlmeIDA, Cláudio Aguiar, «O cinema brasileiro no Estado Novo: o diálogo com Itália, Alemanha e URSS» (Revista de Sociologia y Politica, n. ${ }^{\circ}$ 12, 1999), pp. 121-129. Barro, Máximo, Participação italiana no cinema brasileiro (São Paulo, SESI- SP editora, 2017).

Bock, Hans-Michael Bock y TöTEBerg Michael (eds.), Das Ufa-Buch: Kunst und Krisen, Stars und Regisseure, Wirtschaft und Politik. Die internationale Geschichte von Deutschlands grösstem Film-Konzern (Frankfurt am Main, Zweitausendeins, 1992).

Bolaños Florido, Leidy Paola, Cine silente: una historia de Hollywood en Colombia (1910-1930) (Medellín, La Carreta Editores, 2020).

Butcher, Pedro, «"Bravo, Sr. Baez!”: O Brasil em The United Artists Around the World» en Anais de Textos Completos do XXIII Encontro SOCINE (São Paulo, SOCINE), pp.1014-1019.

Department Of Commerce, Bureau of Foreign and Domestic Commerce (ed.), Motion Picture in Argentina and Brazil. Trade Information Bulletin, n. $\left.^{\circ} 630,1929\right)$.

Feldman, Gerald D., Hugo Stinnes: Biographie eines Industriellen, 1870-1924 (Múnich, C.H.Beck, 1998). 
Freira, Rafael de Luna, «Gustavo Zieglitz e a Empresa Cinematográfica Pathé», Caderno de Resumos, III. Jornada de estúdios em história do cinema brasileiro, III. Fórum de Pesquisas em História do Cinema Brasileiro (Universidade Federal de São Carlos, 2019)

FunrmanN, Wolfgang, «A Ufa no Brasil: cinemas, empresários, e audiências», en Anais do Textos Completos do XXII Encontro da SOCINE 2018 (São Paulo, Socine, 1084-1089).

—, «Transnational Film History? Um Cinema Teuto-Brasileiro», en Anke Finger, Gabi Kathöfer y Christopher Larkosh (eds.), KulturConfusão - On German-Brazilian Interculturalities (Berlín/Boston, De Gruyter, 2015), pp. 179-197.

Isolan Bugatti, Flaviano, Filmabsatzgebiet Brasilien: Die Rezeption des deutschen Films in Brasilien in den 1920er und 30er Jahren (Tesis doctoral, Berlín, Universidad Técnica de Berlín, 2010).

—, Das páginas à tela: cinema alemão e imprensa na década de 1930 (Santa Cruz do Sul, Edusinc, 2006).

Johnson, Randal, Film Industry in Brazil: Culture and the State (Pittsburgh, University of Pittsburgh Press, 1987).

KoIfman, Fábio, «O governo Vargas e a política externa brasileira (1930-1945)», en Jorge Ferreira y Lucília de Almeida Neves Delgado (Org.), O Brasil Republicano. O tempo do nacional-estatismo: do início da década de 1930 ao apogeu do Estado Novo: Segunda República (1930-1945) (Río de Janeiro, Civilização Brasileira, 2019).

KreimeIER, Klaus, Die Ufa-Story: Geschichte eines Filmkonzerns (Múnich, Hanser, 1992).

LESCH Paul Lesch, Heim ins Ufa-Reich?: NS-Filmpolitik und die Rezeption deutscher Filme in Luxemburg 1933-1944 (Trier, Wissenschaftlicher Verlag Trier, 2002).

Moniz-BANDeIRA, Luiz Alberto, Wachstumsmarkt Brasilien. Der deutsche Wirtschaftsund Handelsbeitrag in Geschichte und Gegenwart (Wiesbaden, Springer Gabler 2013).

Nicolás Meseguer, Manuel, Hispano Film Produktion, Una aventura españolista en El cine del Tercer Reich (1936-1944) (Santander, Shangrila, 2017).

Noronha, Jurandyr, Dicionário Jurandyr Noronha de Cinema Brasileiro: Os que vieram de outras terras (Río de Janeiro, EMC Edições, 2015).

Paz, María Antonia y Montero, Julio, La larga sombra de Hitler. El cine nazi en España (1933-1945) (Madrid, Cátedra, 2009).

PEÑA, Fernando Martín, «Metropolis Found». Disponible en:

$<$ https://web.archive.org/web/20141016052747/http://www.fipresci.org/under current/issue_0609/pena_metropolis.htm $>$

Reyes, Aurelio de los, «El cine alemán y el cine soviético en México en los años veinte» (Journal of Film Preservation, n. $^{\circ}$ 60/61, 2000).

RoHland, Regula, «Franka Bindernagel: Deutschsprachige Migranten in Buenos Aires. Geteilte Empfindungen und umkämpfte Geschichtsbilder 1910-1932» (Iberoamericana, vol. 19, n. $\left.{ }^{\circ} 71,2019\right)$.

Rother, Rainer y Thomas, Vera, Linientreu und populär: Das Ufa-Imperium 1933-1945 (Berlín, Bertz + Fischer, 2017).

SANTORo Freire, Paula: «Da relacão das salas de cinema com o urbanismo moderno na construção de uma centralidade metropolitana: A Cinelandia Paulistana». Disponible en: 
$<$ https://www.academia.edu/12103273/A_rela\%C3\%A7\%C3\%A3o_das_sa las_de_cinema_com_o_urbanismo_moderno_na_constru\%C3\%A7\% C 3\% A 3 o _de_uma_centralidade_metropolitana_a_Cinel $\%$ C3\%A2ndia_Paulistana.> (05/05/20). SCHIweCK; Ingo, «[...] weil wir lieber im Kino sitzen als in Sack und Asche»: der deutsche Spielfilm in den besetten Niederlanden 1940-1945 (Múnich, Waxmann, 2002).

SIEREK, Karl, Der lange Arm der Ufa. Filmische Bilderwanderung zwischen Deutschland, Japan und China. 1923-1949 (Wiesbaden, Springer, 2018).

Thompson, Kristin, Exporting Entertainment: America in the World Film Market 1907-1934 (Londres, British Film Institute, 1985).

Vande Winkel, Roel y Welch, David, Cinema and the Swastika: The International Expansion of Third Reich Cinema (Basingstoke, Palgrave Macmillan, 2007).

WAHL, Chris, Sprachversionsfilme aus Babelsberg: die internationale Strategie der Ufa 1929-1939 (Múnich, Edition Text und Kritik, 2009).

Recibido: 13 de mayo de 2020

Aceptado para revisión por pares: 18 de mayo de 2020

Aceptado para publicación: 27 de agosto de 2020 